Байгуисова Аклима Ирлановна,

руководитель проектов,

ООО «АЛП-информационные системы»»,

2. Москва, Россия

\title{
АВТОМАТИЗИРОВАННАЯ СИСТЕМА УПРАВЛЕНИЯ ДОГОВОРАМИ
}

В статье рассматриваются вопросы построения автоматизированной системы управления процессом договорной деятельности на предприятии. Приведены принципы её построения, описаны основные процессы, структура и состав функциональных модулей.

Ключевые слова: договор, дополнительное соглашение, контрагент, пролонгация договора, приложенные документы, график платежей, контроль над дебиторской/кредиторской задолженностью, исполнение обязательств по договору.

\author{
Aklima I. Bayguisova, \\ project manager, \\ $L L C « A L P$-information systems», \\ Moscow, Russia
}

\section{AUTOMATED CONTRACT MANAGEMENT SYSTEM}

The article is devoted to the issues concerning the building of an automated process management system of contractual activities in the enterprise. The article presents the principles of its building and describes the basic processes, structure and composition of functional modules.

Keywords: contract, supplementary agreement, a contractor, prolongation of a contract, appended documents, schedule of payments, control over accounts receivable or/and accounts payable, performance of obligations under a contract.

Ежедневно на любом предприятии возникает потребность в использовании договоров, спецификаций, дополнительных соглашений и приложений к ним, поскольку указанные позиции составляют до $25 \%$ документов в типичной организации.

В настоящее время конкурентоспособность организации в значительной мере определяется её способностью быстро и эффективно реагировать на происходящие перемены, поэтому постоянное улучшение - один из ключевых 
принципов деятельности любой организации, стремящейся не просто выжить, а успешно осуществлять свою деятельность в долгосрочной перспективе [1].

Работы, связанные с обработкой, согласованием и поиском данных договоров занимают большое количество времени. А срывы сроков исполнения обязательств приводят к большим финансовым потерям. Большие объёмы данных договоров инициируют потребность в автоматической регистрации договоров и учёте их состояния сотрудниками организации.

Решением данной проблемы может стать внедрение автоматизированной системы управления договорами на предприятии, полностью удовлетворяющей основные потребности компаний в учёте договорной деятельности.

Существует ряд информационных систем для решения следующих задач по направлению «Договоры»: формирование проекта договора, формирование итоговой карточки договора, формирование дополнительных соглашений, хранение скан-образов документов, согласование, исполнение, завершение и пролонгация договоров. Данные задачи решаются на основе различных платформ: «Docsvision», «1C: Предприятие», «DIRECTUM». Однако ни одна из указанных систем не обеспечивает комплексную автоматизацию вышеперечисленных задач.

При анализе рынка по критерию «цена-качество» можно выделить разработку «Управление договорами», направленную на автоматизацию договорной деятельности компаний.

Понятие «моделирование бизнес-процессов» пришло в быт большинства аналитиков одновременно с появлением на рынке сложных программных продуктов, предназначенных для комплексной автоматизации управления предприятием [2]. Задачей автоматизации процесса управления договорами является создание единой базы договоров и обеспечение мониторинга этапов подготовки, согласования, подписания, регистрации, исполнения договоров Заказчика. Система должна обеспечить возможность ведения договоров от начала процесса инициации проекта договора до процесса завершения обработки договора. 


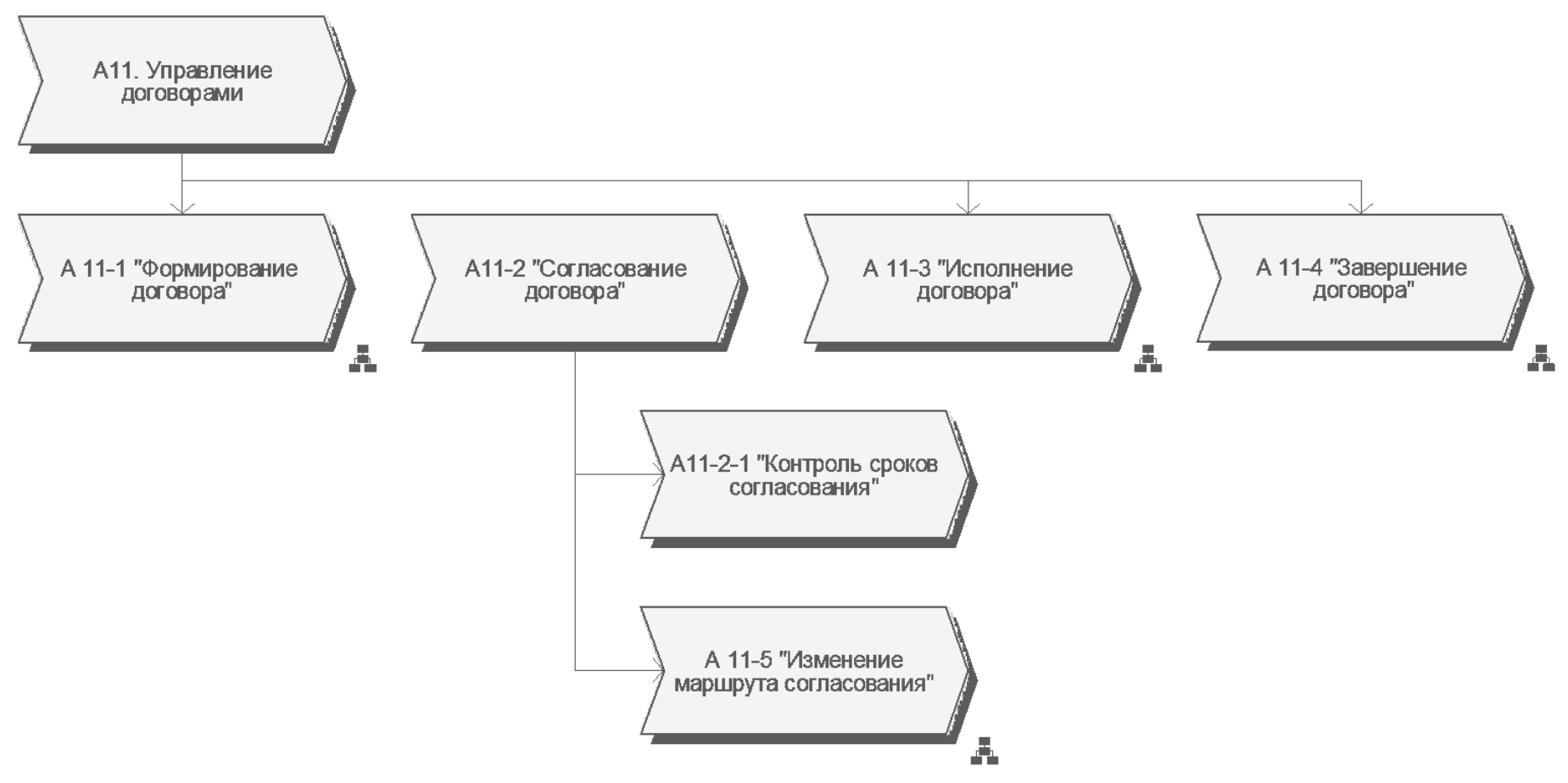

Рисунок 1 - Общая схема бизнес-процесса

Процесс управления договорами представляет собой совокупность следующих действий:

- формирование шаблонов условий договоров (условия оплаты, условия поставки, тарифы);

• настройка шаблонов договоров;

- формирование проекта договора на основании шаблона договора и шаблонов условий, а также содержимого полей карточки договора;

- формирование итоговой карточки договора (рис. 2.);

- формирование дополнительных соглашений.

- классификацию карточек договоров в рамках справочников классов и видов договоров;

- формирование иерархии карточек;

• возможность прикрепления к карточкам электронных документов и скан-образов документов;

- согласование договора;

- исполнение договора;

- автопролонгация договора; 
• закрытие вследствие исполнения обязательств по договору.

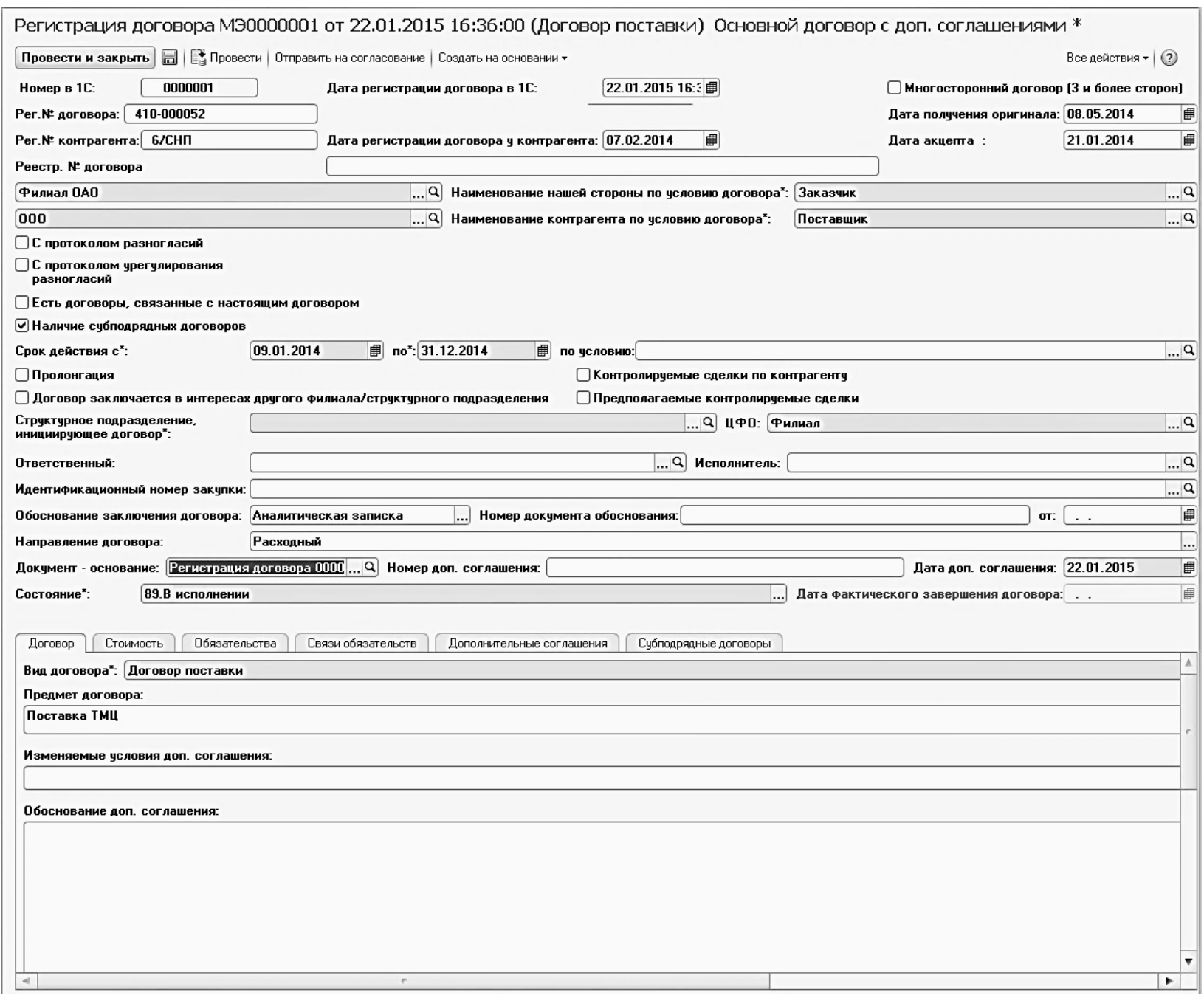

Рисунок 2 - Формирование итоговой карточки договора

Разрабатываемый программный продукт позволит оптимизировать работы, связанные с последовательностью действий по подготовке, согласованию и заключению договоров с контрагентами, а также отслеживанию хода исполнения договоров.

Основные преимущества от внедрения «Управление договорами»:

- ускорение процесса согласования договора ответственными лицами (стандартные и настраиваемые бизнес-процессы);

• формирование отчётности контроля исполнительской дисциплиной сотрудников, участвующих в жизненном цикле договора; 
• автоматическая проверка ключевых параметров договора (сумма, сроки исполнения и т.п.), для минимизации рисков исковых заявлений о неисполнении обязательств по договору;

- функция «умный контроль» позволит инициатору задачи сократить время на проверку, а исполнителю не упустить из виду поручение. Основным преимуществом является возможность индивидуальной настройки критериев для проверки результата, что обеспечивает гибкость и простоту использования;

• получение детальной информации по исполнению мультивалютных договоров.

СПИСОК ЛИТЕРАТУРЫ

1. Ханова А.А. Концеепџия системь интеллектуального управления стратегическиориентированным предприятием // Экономика, статистика и информатика. Вестник УМО. - 2011. - № 1. - C. 187-193.

2. Калянов Г.Н. Моделирование, анализ, реорганизацฺи и автоматизациия бизнес проиессов. M., 2006. $-309 c$. 